\title{
GENETIC PARAMETERS IN FIBRE TRAITS FROM A FULL DIALLEL OF EUCALYPTUS UROPHYLLA IN SOUTHERN CHINA
}

\author{
Wu SJ, Xu JM, Lu ZH*, Guo WZ, Zhou L \& Li GY \\ Research Institute of Tropical Forestry, Chinese Academy of Forestry, Guangdong Guangzhou 510520, China \\ *wushijun0128@163.com
}

Submitted September 2018, accepted March 2019

\begin{abstract}
Fibre traits were assessed for $6 \times 6$ full-diallel families of Eucalyptus urophylla measured at 10 years old. Analysis of variance showed that there were significant combination effects and no block differences on any fibre traits except fibre width. The mean fibre length, fibre width, fine percent, mean curl, fibre kink index and kink angle of controlled crossed families were $0.57 \mathrm{~mm}, 19.74 \mu \mathrm{m}, 27.38 \%, 0.039^{\circ}, 0.64$ and $8.24^{\circ}$ respectively. The heritability of fibre traits was at low to middle level, and the coefficients of variation ranged from 8.58 (width) to $39.30 \%$ (kink angel). Inbreeding depressions of fibre length and width were observed in most families, and the largest inbreeding depressions were estimated at -61.76 and $-15.45 \%$. Heterosis ranged from -42.42 to $103.84 \%$. Kink angle had higher general combining ability and fine percent had higher estimation of specific combining ability. Genotypic correlation between fibre length and fibre width were positive, implying these two traits could be selected simultaneously. As an important indicator of pulp yield, fibre traits should be used for breeding E. urophylla.
\end{abstract}

Keywords: Heterosis, breeding strategy, fibre length, fibre width, kink index

\section{INTRODUCTION}

After more than 30 years of testing and domestication, the genetic improvement in wood volume of Eucalyptus is remarkable. Unfortunately, the mean annual harvest in volume of eucalypt plantations in China is lower than that in the tropical and subtropical regions of the other parts of the world (Xu 2003, Toit et al. 2010). Thus, greater effort to improve productivity of eucalypt plantations in China should be put into practice.

The diallel mating system is an altered factorial design in which the same individuals (or lines) are used as both male and female parents (Huber et al. 1992). Diallel mating design is an important tool in tree breeding because it can provide breeders useful genetic information, such as general combining ability (GCA), specific combining ability (SCA) and heterosis to help them devise appropriate breeding and selection strategies (Yanchuk 1996, Xiang \& Li 2001, Zhang et al. 2005). Extensive studies of diallel mating design have been reported for Eucalyptus species, such as for E. grandis (Wyk 1976), E. globulus (Bison et al. 2007, Rix et al. 2012), E. nitens (Volker et al. 2008) and E. urophylla (Bison et al. 2007, Retief \& Stanger 2009, Wu et al.
2015). Li et al. (2002) reported that growth traits and stem properties of E. globulus are controlled by GCA, SCA and specific reverse cross effects. Heterosis, or hybrid vigour, is a phenomenon in which $\mathrm{F}_{1}$ hybrids perform better than their parents in terms of biomass, yield or resistance to environmental challenges (Dapp et al. 2015). Heterosis is a quicker, cheaper and easier method of increasing plant production (Kalhoro et al. 2015). Genetic improvement of wood properties affecting the quality of pulpwood products is of general interest to tree breeders worldwide (Blackburn et al. 2012). Fibre traits are essential for pulpwood and paper quality and include fibre length, fibre width, fine percent, mean curl, kink index and kink angle. The fibre with higher length, greater width and higher fine percent has higher intensity while the fibre with higher mean curl, kink index and kink angle has higher water absorption.

Eucalyptus urophylla is naturally distributed on mountain slopes and valleys of the large island of Timor and the nearby Indonesian islands of Wetar, Alor, Pantar, Lomblen, Adonara and Flores (Wright \& Osorio 1996, Kien et al. 2008). Eucalyptus urophylla was introduced into southern 
China in the 1980s under the Australia-China Program of Technical Cooperation (McKenney 1998). It has since become a very important plantation species in tropical and subtropical areas in China (Chen et al. 2006, He et al. 2012). More than $50 \%$ of widely used clones in China were established with germplasm derived from E. urophylla and interspecific hybridisation with E. urophylla via controlled pollination (Luo et al. 2010, Wu et al. 2013, Chen et al. 2018). Comprehensive research results about provenance trials, family tests and clone selection of E. urophylla were published in recent years (Retief \& Stanger 2009, Andrade et al. 2013). Unfortunately, full diallel analysis, especially estimation of GCA, SCA and heterosis have not been used very much in E. urophylla improvement.

In this paper, we compared the variance of different combinations, estimated the coefficients of variation of different fibre traits, examined the GCA and SCA and investigated heterosis value of different crosses from 6 $\times 6$ full diallel E. urophylla trials at 10 years old. This information will be used to develop appropriate breeding strategies for this species in southern China.

\section{MATERIALS AND METHODS}

\section{Plant materials and trait measurement}

The trials were established at Du-hui $\left(22^{\circ}\right.$ $33^{\prime} \mathrm{N}, 113^{\circ} 03^{\prime} \mathrm{E}, 45 \mathrm{~m}$ asl) in Jiangmen city of Guangdong Province in April 2006. Maximum rainfall occurs during summer, while winters are generally dry and cool. The mean rainfall per year is $1750 \mathrm{~mm}$. The soil is classified as lateritic red earth. Organic content, $\mathrm{pH}$, total $\mathrm{N}$, total $\mathrm{P}$, total $\mathrm{K}$ and average $\mathrm{B}$ are $29.98 \mathrm{~g} \mathrm{~kg}^{-1}$,
$4.51,1.22 \mathrm{~g} \mathrm{~kg}^{-1}, 0.42 \mathrm{~g} \mathrm{~kg}^{-1}, 11.52 \mathrm{~g} \mathrm{~kg}^{-1}$ and $0.26 \mathrm{~g} \mathrm{~kg}^{-1}$ respectively. The field design was a randomised complete block with six replications and five-tree line plots planted at spacing $3.0 \mathrm{~m}$ $\times 2.0 \mathrm{~m}$. Planting pits $(50 \mathrm{~cm} \times 50 \mathrm{~cm} \times 40 \mathrm{~cm})$ were prepared and compound fertiliser was applied in the first two years with individual tree applications. The $6 \times 6$ full-diallel mating design was made in August to October 2004. Thirty-four full diallel combinations and open pollination families of six parents were collected in April 2005 (Table 1) and used in this trial.

Increment cores (5-mm diameter) were collected from two of five trees in one plot and 12 samples were collected from each family in the trial. Cores were macerated using a sodium hydroxide and peracetic acid digestion (Kube et al. 2001, Wu et al. 2011). Fibre traits including fibre length, fibre width, fine percent, mean curl, kink index and kink angle were measured on 10,000 randomly selected fibres from each core using a fibre analyser.

\section{Statistical analysis}

Statistical analyses were conducted using ASreml package in $\mathrm{R}$ statistic software to detect difference of variance. The linear model on one trait, $y_{\mathrm{ijk} k}$, is:

$$
\mathrm{y}_{\mathrm{ijkl}}=\mu+\mathrm{B}_{\mathrm{i}}+\mathrm{F}_{\mathrm{j}}+\mathrm{M}_{\mathrm{k}}+\mathrm{S}_{\mathrm{jk}}+\mathrm{R}_{\mathrm{jk}}+\mathrm{P}_{\mathrm{ijk}}+\mathrm{e}_{\mathrm{ijkl}}
$$

where $\mu$ = general mean, $B_{i}=$ fixed effect of replicate $i, F_{j}$ and $M_{k}=$ GCA of female $j$ and male $k$ (random effect), $S_{j k}=$ SCA of parents $j$ and $\mathrm{k}$ (random effect), $\mathrm{R}_{\mathrm{jk}}=$ random effect of the specific cross (reciprocal effect) between female $\mathrm{j}$ and male $\mathrm{k}, \mathrm{P}_{\mathrm{ijk}}=$ random effect of individual and $\mathrm{e}_{\mathrm{ijkl}}=$ random residuals (Fukatsu et al. 2013). Narrow sense heritability $\left(h^{2}\right)$ derived from both male and female parents was estimated as:

Table 1 Full-diallel mating design between six Eucalyptus urophylla parents

\begin{tabular}{ccccccc}
\hline \multirow{2}{*}{ Female } & \multicolumn{7}{c}{ Male } \\
\cline { 2 - 7 } & U2 & U21 & U22 & U56 & U64 & DU1 \\
\hline U2 & $\odot$ & $\times$ & $\times$ & $\times$ & $\times$ & $\times$ \\
U21 & $\times$ & $\odot$ & $\times$ & $\times$ & $\times$ & $\times$ \\
U22 & $\times$ & $\times$ & $\odot$ & $\times$ & $\times$ & $\times$ \\
U56 & $\times$ & $\times$ & $\times$ & $\odot$ & $\times$ & $\times$ \\
U64 & $\times$ & $\times \#$ & $\times$ & $\times$ & $\odot$ & $\times$ \\
DU1 & $\times$ & $\times$ & $\times$ & $\times$ & $\times$ & $\odot$ \\
\hline
\end{tabular}

$x=$ cross combination, $\odot=$ inbreeding combination, $\#=$ combination seeds were not obtained 


$$
\mathrm{h}^{2}=2\left({\sigma_{\mathrm{f}}^{2}}^{2}+{\sigma_{\mathrm{m}}^{2}}^{2}\right) /\left({\sigma_{\mathrm{f}}^{2}}^{2}+\sigma_{\mathrm{m}}^{2}+\sigma_{\mathrm{fm}}^{2}+\sigma_{\mathrm{e}}^{2}\right)
$$

where $\sigma_{\mathrm{f}}^{2}, \sigma_{\mathrm{m}}^{2}, \sigma_{\mathrm{fm}}^{2}$ and $\sigma_{\mathrm{e}}^{2}$ are female effect, male effect, female and male interaction effect and error effect respectively.

The genotypic coefficient of variation (CV) was calculated as (Pliura et al. 2007, Hai et al. 2008):

$$
\mathrm{CV}=\left(100 \sigma_{\mathrm{c}} / \mathrm{x}\right) \times 100 \%
$$

where $\sigma_{\mathrm{c}}=$ genetic variance and $\mathrm{x}=$ phenotypic mean. The equation expresses a standardised measure of the genetic variance relative to the mean of trait. Inbreeding depression $\left(D_{i}\right)$ was estimated following Jin et al. (2009):

$$
\mathrm{D}_{\mathrm{i}}=\left(\mathrm{F}_{\mathrm{si}}-\mathrm{OP}\right) / \mathrm{OP} \times 100 \%
$$

where $\mathrm{F}_{\mathrm{si}}=$ average value of studied traits for inbred families of parents and $\mathrm{OP}=$ average value of studied traits for open pollination families of parents.

$\mathrm{F}_{1}$ hybrid heterosis was calculated as follows (Bahman et al. 1975):

$$
\mathrm{H}=\left(\mathrm{F}_{\mathrm{i}}-\mathrm{OP}\right) / \mathrm{OP} \times 100 \%
$$

where $F_{i}=$ average value of studied traits for hybrid families, OP = average value of studied traits for open pollination families of better parent. The genotypic correlation, $\mathrm{r}_{\mathrm{A}(\mathrm{xy})}$, of traits $\mathrm{x}$ and $\mathrm{y}$ was calculated as (Pliura et al. 2007, Stackpole et al. 2010):

$$
r_{A(x y)}=\frac{\sigma_{a(x y)}}{\sqrt{\sigma_{a(x)}^{2} \times \sigma_{a(y)}^{2}}}
$$

where $\sigma_{\mathrm{a}(\mathrm{x})}^{2}=$ genetic variance components for the trait $\mathrm{x}, \sigma_{\mathrm{a}(\mathrm{y})}^{2}=$ genetic variance components for the trait $y$ and $\sigma_{a(x y)}^{2}=$ additive covariance component.

\section{RESULTS}

\section{Variance among families and blocks}

The analyses of variance of studied fibre traits among blocks, family, male and female are listed in Table 2. The results showed that there were no significant block differences in all fibre traits except fibre width and no significant block $\times$ family difference for all fibre traits, indicating that fibre width was affected by environment. The joint analysis of all families showed significant family effects for all fibre traits except fibre width. This suggested that there was less difference in fibre width between combinations. Furthermore, there were significant differences in fibre width, mean curl, kink index and kink angle among females and significant differences in fibre width and mean curl among males, and fine percent and mean curl between female $\times$ male effect.

\section{Trait mean, heritability and genetic variation}

Mean value, heritability and coefficient variation of the studied fibre traits are presented in Table 3. Open-pollinated families had longer mean fibre length than controlled crossed families, whereas the mean values of fibre width, fine percent, mean curl, kink index and kink angle of the

\begin{tabular}{|c|c|c|c|c|c|c|c|c|c|c|c|c|}
\hline \multirow[t]{2}{*}{ Trait } & \multicolumn{2}{|c|}{ Block } & \multicolumn{2}{|c|}{ Progeny } & \multicolumn{2}{|c|}{ Block $\times$ progeny } & \multicolumn{2}{|c|}{ Female } & \multicolumn{2}{|c|}{ Male } & \multicolumn{2}{|c|}{ Female $\times$ male } \\
\hline & $\mathrm{F}$ & $\mathrm{P}$ & $\mathrm{F}$ & $\mathrm{P}$ & $\mathrm{F}$ & $\mathrm{P}$ & $\mathrm{F}$ & $\mathrm{P}$ & $\mathrm{F}$ & $\mathrm{P}$ & $\mathrm{F}$ & $\mathrm{P}$ \\
\hline Fibre length & 0.55 & 0.8134 & 1.64 & 0.0226 & 1.02 & 0.4626 & 1.70 & 0.1352 & 1.96 & 0.0862 & 1.57 & 0.0537 \\
\hline Fibre width & 3.87 & 0.0005 & 1.39 & 0.0936 & 0.61 & 0.9966 & 2.55 & 0.0288 & 3.99 & 0.0018 & 0.88 & 0.6316 \\
\hline Fine percent & 1.21 & 0.2949 & 2.09 & 0.0013 & 1.06 & 0.3790 & 1.58 & 0.1661 & 1.16 & 0.3292 & 2.38 & 0.0007 \\
\hline Mean curl & 1.38 & 0.2131 & 1.86 & 0.0059 & 0.68 & 0.9848 & 6.03 & $<0.0001$ & 2.38 & 0.0400 & 1.62 & 0.0409 \\
\hline Kink index & 1.66 & 0.1147 & 1.99 & 0.0025 & 0.78 & 0.9160 & 6.92 & $<0.0001$ & 1.81 & 0.1115 & 1.57 & 0.0536 \\
\hline Kink angle & 1.66 & 0.1151 & 1.83 & 0.0072 & 0.73 & 0.9589 & 6.87 & $<0.0001$ & 1.16 & 0.3278 & 1.55 & 0.0568 \\
\hline
\end{tabular}
latter were greater than the former. Heritability of studied fibre traits had middle to low value ( 0.2 is middle, $>0.4$ is high). Fibre width had

Table 2 Variance analysis for fibre traits of Eucalyptus urophylla

$\mathrm{F}=\mathrm{F}$-ratio, $\mathrm{P}=$ the probability of the F-ratio 
the highest heritability estimation than other traits, and fine percent had the lowest heritability estimation. The coefficient of variation of fibre ranged from 8.58 to $39.30 \%$. Kink index had the highest estimation value compared with the rest of the traits, and fibre width had the lowest estimation.

\section{Inbreeding depression analysis}

The estimates of inbreeding depression for studied fibre traits are listed in Table 4. Inbreeding depression of fibre length was observed in parents U2, U21, U56, U64 and DU1 while U64 had the largest inbreeding depression. Inbreeding depression of fibre width was observed in parents U21, U56 and U64 while U64 had the largest inbreeding depression. The depression of fine percent, mean curl, kink index and kink angle ranged from -67.16 to $205.20 \%$. DU1 had positive inbreeding depression value of fibre width and negative inbreeding depression value of the rest of the traits.

\section{Heterosis estimation}

Estimations of heterosis on fibre traits in $E$. urophylla families are given in Table 5 . For positive heterosis, fibre length, fibre width, fine percent, mean curl, kink index and kink angle were estimated at -30.63 to $4.44 \%,-9.20$ to $10.74 \%$, -22.25 to $62.36 \%,-19.21$ to $51.79 \%,-28.04$ to 54.27 and -25.64 to $94.62 \%$ respectively. U56 $\times$ DU1 had the highest positive heterosis estimation on kink angle while U2 $\times$ U64 had the lowest positive heterosis estimation on fibre length. On the other hand, the reverse heterosis estimation on fibre length, fibre width, fine percent, mean curl, kink index and kink angle were -26.47 to $16.35 \%,-8.68$ to $9.07 \%,-42.42$ to $75.55 \%,-18.48$ to $70.50 \%,-31.68$ to 61.78 and -31.22 to $103.84 \%$ respectively. U56 $\times$ U21 had the highest reverse heterosis estimation on kink angle, while U64 $\times$ U2 had the lowest reverse heterosis estimation on fine percent.

\section{Estimation of GCA and SCA}

The estimation of GCA and top 10 SCA of fibre traits between crosses are listed in Tables 6 and 7. The results showed that kink angle had higher GCA estimation, and fine percent had smaller GCA estimation (Table 6). Different parents had similar GCA estimation of fine percent. DU1 had higher GCA estimation on fibre length and fibre width and lower GCA estimation on mean curl, kink index and kink angle. Fine percent had higher SCA estimation and mean curl had smaller GCA estimation (Table 7). SCA estimation for fibre length was relatively higher

Table 3 Mean values for traits, heritability $\left(\mathrm{h}^{2}\right)$ and coefficient of variation (CV) of Eucalyptus urophylla fibre

\begin{tabular}{|c|c|c|c|c|c|c|}
\hline Type & $\begin{array}{l}\text { Fibre length } \\
(\mathrm{mm})\end{array}$ & $\begin{array}{l}\text { Fibre width } \\
\qquad(\mu \mathrm{m})\end{array}$ & Fine percent & $\begin{array}{c}\text { Mean curl } \\
(\stackrel{9}{)})\end{array}$ & Kink index & $\begin{array}{c}\text { Kink angle } \\
\left({ }^{\circ}\right)\end{array}$ \\
\hline Controlled crossed families & 0.57 & 19.74 & 27.38 & 0.039 & 0.64 & 8.24 \\
\hline Open-pollinated families & 0.59 & 19.61 & 27.15 & 0.037 & 0.61 & 7.83 \\
\hline$h^{2}$ & $0.08(0.09)$ & $0.19(0.13)$ & $0.01(0.06)$ & $0.14(0.13)$ & $0.18(0.15)$ & $0.14(0.12)$ \\
\hline $\mathrm{CV}(\%)$ & 19.90 & 8.58 & 8.98 & 27.50 & 39.30 & 39.01 \\
\hline
\end{tabular}

Table 4 Inbreeding depression of fibre traits (\%) of Eucalyptus urophylla

\begin{tabular}{ccccccc}
\hline Parent & Fibre length & Fibre width & Fine percent & Mean curl & Kink index & Kink angle \\
\hline U2 & -21.34 & 6.22 & 53.53 & 38.89 & 89.70 & 77.30 \\
U21 & -38.04 & -9.52 & 113.43 & 122.22 & 205.20 & 193.52 \\
U22 & 37.81 & 11.11 & -61.28 & 7.14 & 12.16 & 15.47 \\
U56 & -9.44 & -5.82 & -20.53 & 47.50 & 54.23 & 50.78 \\
U64 & -61.76 & -15.45 & 190.01 & 57.14 & 61.40 & 54.74 \\
DU1 & -1.32 & 8.42 & -16.79 & -40.00 & -67.16 & -67.32 \\
\hline
\end{tabular}



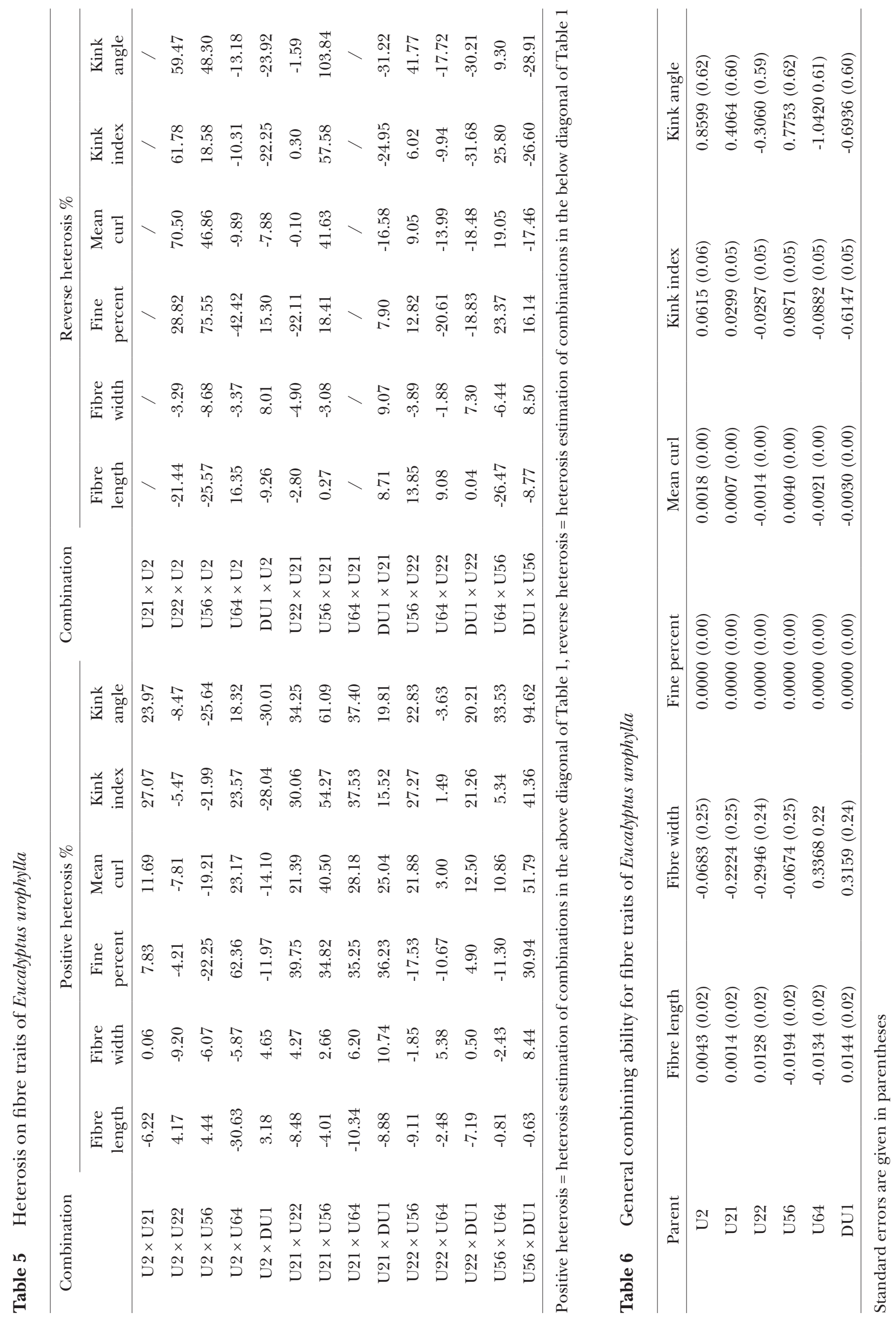


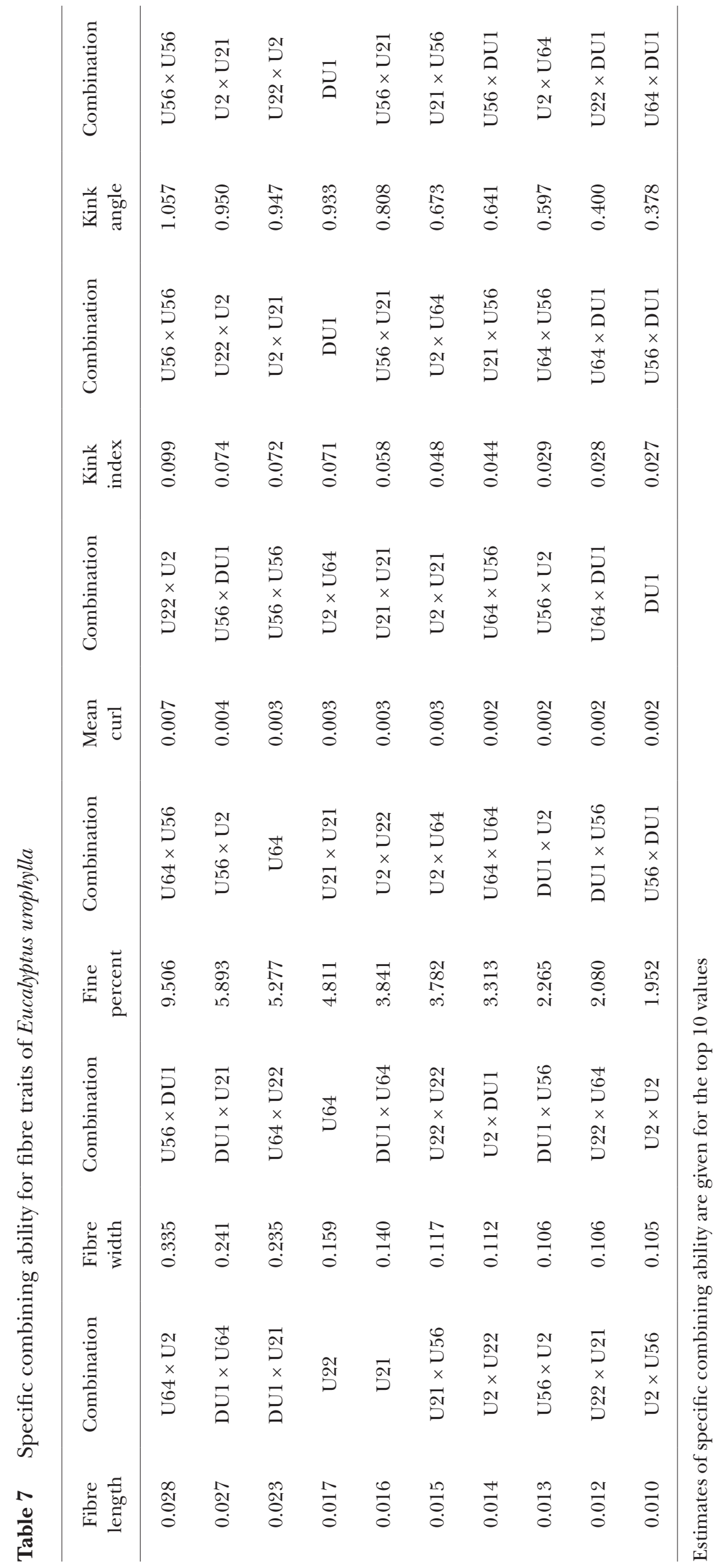


in U22 and U21 open-pollinated combinations than the rest of the parents while U64 had higher SCA estimation for fibre width. SCA estimation was highest in $\mathrm{U} 64 \times \mathrm{U} 56$, U22 $\times \mathrm{U} 2$, U56 $\times \mathrm{U} 56$ and U56 $\times$ U56 for fine percent, mean curl, kink index and kink angle respectively.

\section{Trait-trait genetic correlation}

Genotypic correlation between fibre traits is listed in Table 8. In this study, fibre length had positive genotypic correlation with fibre width and fine percent, ranging from 0.06 to 0.38 . However, both fibre length and fibre width had negative correlation values with mean curl, kink index and kink angle, ranging from -0.36 to -0.99. Generally, there were strong positive genotypic correlation values between fine percent, mean curl, kink index and kink angle, ranging from 0.27 to 1.00 .

\section{DISCUSSION}

\section{Means and genetic parameters of traits}

Higher fibre length could improve the quality of paper. In the study, the present mean fibre length values of all the families (Table 3) are shorter than the widely used eucalypt hybrid clones (Yao et al. 2003, Wu et al. 2011), indicating that more attention should be paid to fibre length in the breeding of pure E. urophylla. Meanwhile fibre width is higher than values reported for E. tereticornis and E. camaldulensis families ( $\mathrm{Lu}$ et al. 2000). The 8-year-old E. tereticornis and E. camaldulensis in Hainan Province, south China had mean values for fibre length ranging from 0.83 to $1.16 \mathrm{~mm}$ and fibre width from 11 to 13 $\mu \mathrm{m}$ (Lu et al. 2000).
Estimates of heritability for fibre traits were low to medium for fibre percent (0.01) and fibre width $(0.19)$, which were in general agreement with the eucalypt hybrids studied by Zhu et al. (2017) (0.04) and Chen et al. (2018) (0.06-0.49). Heritability of fibre width was higher than that of fibre length, indicating more genetic gain could be obtained from fibre width by genetic improvement as previously found by Wu et al. (2011).

The coefficient of variation of fibre traits in this study ranged from $8.58 \%$ for fibre width to $39.30 \%$ for kink angle (Table 3 ). The coefficient of variation of fibre width was in general agreement with the variability observed by $\mathrm{Wu}$ et al. (2011). However, the coefficient of variation of fibre length was larger than published papers, implying that the selection gain would be limited.

\section{Inbreeding is useful for improvement}

Inbreeding has been recognised as an important research tool for forest genetics and breeding because it impacts the heredity structure and substantially increases reproductive ability as well as seed quality and quantity (Chen et al. 1989). However, improvement in fibre length and fibre width was observed in inbred crosses of parent U22 suggesting that inbred parent U22 could be used for E. urophylla improvement in China. Generally speaking, different parents had different inbreeding depression on different fibre traits. It was interesting to find that there was no inbreeding depression on mean curl, kink index and kink angle in inbreeding of parents U2, U21, U22, U56 and U64. This meant that their inbred offspring could improve water absorption of paper.

Table 8 Genotypic correlations between fibre traits of Eucalyptus urophylla

\begin{tabular}{|c|c|c|c|c|c|}
\hline Trait & Fibre width & Fine percent & Mean curl & Kink index & Kink angle \\
\hline Fibre length & $0.34(0.45)$ & $0.38(0.30)$ & $-0.79(0.51)$ & $-0.36(0.32)$ & $-0.66(0.48)$ \\
\hline Fibre width & & $(0.06)(0.15)$ & $-0.99(1.57)$ & $-0.80(0.31)$ & $-0.89(0.33)$ \\
\hline Fine percent & & & $0.79(0.53)$ & $0.67(1.48)$ & $0.48(1.37)$ \\
\hline Mean curl & & & & $1.00(0.13)$ & $0.27(1.05)$ \\
\hline Kink index & & & & & $1.00(0.01)$ \\
\hline
\end{tabular}

Standard errors are given in parentheses 
Different combinations had different positive and reverse heterosis

Heterosis values were estimated as the percentage deviation of the $F_{1}$ performance from the midparent, better parent and best parent (Paramathma et al.1997). In general, the estimation range of reverse heterosis was greater than that of positive heterosis (Table 5). The positive and reverse heterosis estimation ranges for fibre length were greater than that for fibre width. The same combinations had different positive and reverse heteroses even for the same traits. For example, the positive and reverse heteroses for fibre length of U2 and U22 were 4.17 and $-21.44 \%$ respectively. Meanwhile U2 $\times$ DU1 and DU1 $\times$ U21 had higher positive and reverse heteroses for fibre length and fibre width. This implied that superior individuals with higher fibre length and width can be selected from these combinations. Bao and Luo (2002) reported that heterosis estimation for growth and wood traits ranged from -9.4 to $23.2 \%$ in 9 -year-old $E$. urophylla.

\section{GCA and SCA analysis}

Combining ability provides a guideline for selecting elite parents and desirable cross combinations to be used in formulation of a systematic breeding project for rapid improvement (Kalhoro et al. 2015). For fibre length and width, U56 had negative GCA effect while DU1 had positive effect (Table 6), indicating DU1 had higher general combining ability and potential to improve fibre length and width simultaneously. It is interesting to find that the GCA effect of kink index may have slight positive correlation with GCA effect of kink angle. For fibre length, U64 $\times$ U2, DU1 $\times$ U64 and DU1 $\times$ U21 had higher SCA estimation while U5 $6 \times$ DU1, DU $1 \times$ U21 and U $64 \times$ U 22 had higher SCA estimation for fibre width (Table 7). This showed that these families could be used for further propagation and breeding.

\section{Genetic correlation between traits}

High genetic correlation value between growth traits and wood properties had been widely described in Eucalyptus and other species (Kien et al. 2009, Kube et al. 2001, Wu et al. 2011, Chen et al. 2018). High genetic correlation indicates that the expression of both traits is most likely controlled by the same class of genes in an organism (Chen et al. 2018). There was positive genotypic correlation between fibre length, fibre width and fine percent, meaning that longer fibre length always had higher fibre width and higher fine percent. Meanwhile positive genotypic correlation values were observed between fine percent, mean curl, kink index and kink angle. However negative genotypic correlation was observed between fibre length and width and mean curl, kink index and kink angle, indicating that higher fibre length and width always had lower mean curl, kink index and kink angle. Our results were consistent with previous studies that reported strong positive correlation between fibre length and fibre width for Eucalyptus hybrid clones in southern China (Wu et al. 2011).

\section{ACKNOWLEDGMENTS}

The authors gratefully thank Harding K and Pegg $\mathrm{R}$ for their help in improving the manuscript and Yang $\mathrm{H}$ from Xinhui Research Institute of Forestry Science for sample preparation. This study was funded by two projects: Genetic Basic of Male Parent Selection on Heterosis of F1 Family in Eucalyptus urophylla (31600545) and Overseas Study Support Plan of International Cooperation (CAFYBB2019GC001-5).

\section{REFERENGES}

Andrade TCGR, Baroos NF, DiAs LE ET AL. 2013. Biomass yield and calorific value of six clonal stands of Eucalyptus urophylla S.T. Blake cultivated in northeastern Brazil. Cerne 19: 467-472. doi:10.1590/S010477602013000300014

Bahman YS, SARAFi A \& Zali AA. 1975. Heterosis and inbreeding estimates in safflower. Crop Science 15: 81-83. doi: 10.2135/cropsci1975.0011183X00150 $0010024 x$.

BAO FC \& LuO JJ. 2002. Inbreeding depression and hybrid superiority in growth and wood traits of eucalypt pulp wood. Journal of Beijing Forestry University 24: 1-6.

Bison O, Ramalho MAP, Rezendegdsp et al. 2007. Combining ability of elite clones of Eucalyptus grandis and Eucalyptus urophylla with Eucalyptus globulus. Genetics and Molecular Biology 30: 417-422.

Blackburn D, Farrell R, Hamilton M et al. 2012. Genetic improvement for pulpwood and peeled veneer in Eucalyptus nitens. Canadian Journal of Forest Research 42: 1724-1732. https://doi.org/10.1139/x2012-105.

Chen Y, Kang L, Dell B. 2006. Inoculation of Eucalyptus urophylla with spores of scleroderma in a nursery in south China: comparison of field soil and potting mix. Forest Ecology and Management 222: 439-449. https://doi.org/10.1016/j.foreco.2005.10.050. 
Chen SK, Weng QJ, Li FG et AL. 2018. Genetic parameters for growth and wood chemical properties in Eucalyptus urophylla $\times$ E. tereticornis hybrids. Annals of Forest Science 75: 16-27. https://doi.org/10.1007/s13595018-0694-x.

Chen Y, He G \& Li G. 1989. Inbreeding depression for seed germinative percent and growth of fir. Forest Research 2: 420-426. (in Chinese)

Dapp M, Reinders J, Bediee A et al. 2015. Heterosis and inbreeding depression of epigenetic Arabidopsis hybrids. Nature Plants 1: 1-8. https://doi. org/10.1038/nplants.2015.92.

Fukatsu E, Tsubomura M, Fujisawa Y \& Nakada R. 2013. Genetic improvement of wood density and radial growth in Larix kaempferi: results from a diallel mating test. Annals of Forest Science 70: 451-459. https://doi.org/10.1007/s13595-013-0278-8.

Hai PH, Jansson G, Harwood C et al. 2008. Genetic variation in growth, stem straightness and branch thickness in clonal trials of Acacia auriculiformis at three contrasting sites in Vietnam. Forest Ecology and Management 255: 156-167. https://doi. org/10.1016/j.foreco.2007.09.017.

He X, Li F, Li M et AL. 2012. Quantitative genetics of cold hardiness and growth in Eucalyptus as estimated from E. urophylla $\times$ E. tereticornis hybrids. New Forests 43: 383-394.

Huber DA, White TL, Littell RC et AL. 1992. Ordinary least squares estimation of general and specific combining abilities from half-diallel mating designs. Silvae Genetica 41: 263-273.

Jin G, QIN G, LiU W ET AL. 2009. Genetic analysis of crossing effects for growth traits of Pinus massoniana and selection of cross combinations. Frontiers of Forestry in China 4: 101-106. doi:10.1007/s11461-009-0011-9.

Kalhoro FA, Rajpar AA, Kaohoro SA et al. 2015. Heterosis and combing ability in $\mathrm{F}_{1}$ population of hexaploid wheat (Triticum aestivum L.). American Journal of Plant Science 6: 1011-1026. doi:10.4236/ajps.2015.67107.

KIEN ND, Jansson G, Harwood C ET AL. 2008. Genetic variation in wood basic density and Pilodyn penetration and their relationships with growth, stem straightness and branch size for Eucalyptus urophylla S.T. Blake in Northern Vietnam. New Zealand Journal of Forestry Science 38: 160-175.

Kien ND, Jansson G, Harwood C et al. 2009. Genetic control of growth and form in Eucalyptus urophylla in northern Vietnam. Journal of Tropical Forest Science 21: 50-65.

Kube PD, Raymond CA \& Banham PW. 2001. Genetic parameters for diameter, basic density, cellulose content and fibre properties for Eucalyptus nitens. Forest Genetics 8: 285-294.

Li D Q, LiU YP, Zeng DX eT AL. 2002. Analysis of genetic effects for growth traits of Eucalyptus globules Labill. in a $6 \times 6$ diallel design. Acta Genetica Sinica 29: 835-840.

Lu Z, Xu J, Bai J et al. 2000. Genetic research on wood properties of Eucalyptus tereticornis and E. camaldulensis. Forest Research 13: 370-376. (in Chinese)

Luo J, Zhou G, Wu B ET AL. 2010. Genetic variation and ageage correlations of Eucalyptus grandis at Dongmen
Forest Farm in southern China. Australian Forestry 73: 67-80. doi:10.1080/00049158.2010.10676312.

McKenney DW. 1998. Australian Tree Species Selection in China. ACIAR Projects 8457 and 8848. Australian Centre for International Agricultural Research, Canberra.

Paramathma M, Surendran C \& Vinaya Rai RS. 1997. Studies on heterosis in six Eucalyptus species. Journal of Tropical Forest Science 9: 283-293.

Pliura A, Zhang SY, Mackay J et al. 2007. Genotypic variation in wood density and growth traits of poplar hybrids at four clonal trials. Forest Ecology and Management 238: 92-106. https://doi.org/10.1016/j. foreco.2006.09.082.

Retief ECL \& Stanger TK. 2009. Genetic control of wood density and bark thickness, and their correlations with diameter, in pure and hybrid populations of Eucalyptus grandis and E. urophylla in south Africa. Southern Forests 71: 147-153. doi:10.2989/ SF.2009.71.2.10.825.

Rix KD, Gracie AJ, Potts BM et al. 2012. Paternal and maternal effects on the response of seed germination to high temperatures in Eucalyptus globulus. Annals of Forest Science 69: 673-679. doi:10.1007/s13595012-0190-7.

Stackpole DJ, Vaillancourt RE, Aguigar MD et al. 2010. Age trends in genetic parameters for growth and wood density in Eucalyptus globulus. Tree Genetics E Genomes 6: 179-193. doi:10.1007/s11295-009-0239-4.

Toit BD, Sмith CW, Little KM et Al. 2010. Intensive, site-specific silviculture: manipulating resource availability at establishment for improved stand productivity. A review of southern African research. Forest Ecology and Management 259: 1836-1845. https://doi.org/10.1016/j.foreco.2009.07.015.

Volker PW, Potts BM, Borralho MG. 2008. Genetic parameters of intra- and inter-specific hybrids of Eucalyptus globulus and E. nitens. Tree Genetics E Genomes 4: 445-460. doi:10.1007/s11295-0070122-0.

Wright JA \& Osorio LF.1996. Comparison of Eucalyptus urophylla provenance performance at half-rotation in Colombia and hybrid strategies with Eucalyptus grandis. Forest Ecology and Management 83: 117-122. doi:10.1016/0378-1127(95)03681-4.

WU S, XU J, Li G ET AL. 2011. Genotypic variation in wood properties and growth traits of Eucalyptus hybrid clones in southern China. New Forests 42: 35-50.

Wu S, XU J, Li G ET AL. 2013. Genetic variation and genetic gain in growth traits, stem-branch characteristics and wood properties and their relationships of Eucalyptus urophylla clones. Silvae Genetica 62: 153-256.

Wu S, Xu J, Lu Z ET AL. 2015. Effects of inbreeding on growth and wood properties of selfed Eucalyptus urophylla progenies. Journal of Tropical Forest Science 27: 369-375.

WYк GV. 1976. Early growth results in a diallel progeny test of Eucalyptus grandis (Hill.) Maiden. Silvae Genetica 26: 44-50.

XIANG B \& Li BL. 2001. A new mixed analytical method for genetic analysis of diallel data. Canadian Journal of Forest Research 31: 2252-2259. doi: 10.1139/cjfr-3112-2252. 
Xu DP. 2003. Scenarios for a commercial eucalypt plantation industry in southern China. Pp 39-45 in Turnbull JW (ed) Eucalypts in Asia. Proceedings of an International Conference. 7-11 April 2003, Zhanjiang.

YANCHUK AD. 1996. General and specific combining ability from disconnected partial diallels of coastal Douglasfir. Silvae Genetica 45: 37-45

Yao Q, He S, Zhang J et al. 2003. Study on selection of Eucalyptus fine clone for timber in southern hilly land of Fujian. Scientia Silvae Sinicae 39: 87-92. (in Chinese)
Zhang YD, Kang MS \& Lamkey KR. 2005. Diallel-SAS05: a comparative program for Griffing's and GardnerEberhart analysis. Agronomy Journal 97: 1097-1106.

Zhu YA, Wu SJ, Xu JM ET AL. 2017. Genetic parameters for growth traits and stem-straightness in Eucalyptus urophylla $\times$ E. camaldulensis hybrids from a reciprocal mating design. Euphytica 213: 142. doi:10.1007/ s10681-017-1923-3. 